\title{
Formulation and evaluation of polyherbal gel containing extracts of Azadirachta indica, Adhatoda vasica, Piper betle, Ocimum tenuiflorum and Pongamia pinnata
}

\author{
Somnath D. BHINGE ${ }^{1}$ *, Mangesh A. BHUTKAR ${ }^{2}$, Dheeraj S. RANDIVE ${ }^{2}$, Ganesh H. WADKAR ${ }^{3}$, \\ Sanjeeva Y. KAMBLE ${ }^{1}$, Pooja D. KALEL ${ }^{1}$, Sneha S. KADAM ${ }^{1}$ \\ 1 Department of Pharmaceutical Chemistry, Rajarambapu College of Pharmacy, Kasegaon, Dist - Sangli, \\ Maharashtra, India . \\ 2 Department of Pharmaceutics, Rajarambapu College of Pharmacy, Kasegaon, Dist - Sangli, Maharashtra, India. \\ 3 Department of Pharmacognosy, Rajarambapu College of Pharmacy, Kasegaon, Dist - Sangli, Maharashtra, India. \\ * Corresponding Author. E-mail: somu1245@yahoo.co.in (S.D.B); Tel. +91 2342 238200; ORCID No: 0000-0002-5959- \\ 5833.
}

Received: 31 January 2018 / Revised: 30 April 2018 / Accepted: 30 April 2018

\begin{abstract}
In the Indian system of medicine-Ayurveda, azadirachta indica, adhatoda vasica, piper betle, ocimum tenuiflorum and pongamia pinnata has been mentioned as a remedy for treatment of various infectious diseases and ailments. Based on the folkloric use, the present study was designed to formulate and evaluate polyherbal gel containing extracts of Azadirachta indica, Adhatoda vasica, Piper betle, Ocimum tenuiflorum and Pongamia pinnata. Gel formulations (Formulation A, B and C) were prepared which comprised of the ethanolic extracts of Azadirachta indica, Adhatoda vasica, Piper betle, Ocimum tenuiflorum and Pongamia pinnata in a concentration of $0.1,0.3$ and $0.5 \%$, respectively in a base. The prepared formulations were evaluated for appearance and homogeneity, $\mathrm{pH}$, viscosity and rheological studies, spreadability, skin irritation test (patch test) and washability. The formulations were also screened for their antimicrobial activity by disc plate method against S. aureus, B. subtilis, A. niger and E. coli. The results of the studies revealed that all formulations under study viz. A, B and C showed better zone of inhibition as compared with the control. However, formulation $C$ exhibited maximum activity against the selected strains which may be attributed to its greater amount of herbal extracts as compared to formulation A and B. The polyherbal gel formulations were observed to possess antimicrobial action. The effective activity may be attributed to the synergistic action of the plants constituents present in the formulation.
\end{abstract}

KEYWORDS: Antimicrobial activity; patch test; polyherbal gel; evaluation test.

\section{INTRODUCTION}

More than $80 \%$ of the world's population still greatly depends upon traditional medicines for treatment of various skin diseases [1]. In the recent years, there has been a gradual revival of interest in the use of medicinal plants in developing countries, as herbal medicines have been reported to be safe with minimal side effects especially when compared with synthetic drugs [2,3]. Herbal treatments applied topically have gained considerable attention due to their widespread use and ill-defined benefit/risk ratio $[4,5]$. There are numerous medicinal plants which are widely used in the treatment of skin diseases and also known to possess antimicrobial activity [6]. Topical application of gels at pathological sites offer great advantages in a faster release of a drug directly to site of action as compared to cream and ointment $[7,8]$.

Azadirachta indica (Neem), is phytochemically rich in steroids, alkaloids, tannins, triterpenes, flavonoid and anthraquinone glycosides $[9,10]$. It has been known to be used traditionally for their various therapeutic properties like antibacterial, antimicrobial, antioxidant, skin disorder, and wound healing activity [11, 12]. Also it has been reported to possess various therapeutic properties like anti-inflammatory, antipyretic, antimalarial, antiulcer, antidiabetic, neuropharmacological effect, anthelmintic activity, antimicrobial and antibacterial effect [13-20]. Ocimum tenuiflorum has been found to exhibit various activities like antioxidant, antidiabetic, chemo preventive effect, anti-ulcer, anticarcinogenic, anti-stress and also useful in modulation of immune response [21-26]. Adhatoda vasica has been reported to be used traditionally for their various medicinal

How to cite this article: Bhinge SD, Bhutkar MA, Randive DS, Wadkar GH, Kamble SY, Kalel PD, Kadam SS. Formulation and evaluation of polyherbal gel containing extracts of Azadirachta indica, Adhatoda vasica, Piper betle, Ocimum tenuiflorum and Pongamia pinnata. J Res Pharm. 2019; 23 (1): 44-54. 
properties like anthelmintic, antiulcer, anticestodal, antioxidant, antifungal, antimicrobial and antibacterial effect [27-29]. Piper betle and Pongamia pinnata have been known to possess various therapeutic properties like antioxidant, antifungal, antimicrobial, hypoglycemic and antibacterial effect [30-36]. As per the literature survey the aforesaid plants have been reported for their antibacterial and antimicrobial effect by different researchers in most of the research articles. Based on this information it was decided to develop a herbal gel containing plant extracts which will possess better activity and prove to be effective against microorganisms. Despite of the fact that these plants possess good antimicrobial action, their use and application on the skin surface in the raw form is difficult. Hence, the present investigation was thus undertaken for preparation of polyherbal gel formulation using ethanolic extracts of Azadirachta indica, Adhatoda vasica, Piper betle, Ocimum tenuiflorum and Pongamia pinnata, so as to facilitate their effective use to exhibit its antimicrobial action. The prepared formulations were thereafter evaluated for their physical appearance, $\mathrm{pH}$, viscosity, spreadability, drug content, skin irritation test, washability and antibacterial activity.

\section{RESULTS}

\subsection{Evaluation of poly herbal gel}

\subsubsection{Physical analysis of the prepared polyherbal gel}

It was observed that the freshly prepared formulations were off white to yellow in color (Table 1). Regarding the base and formulation $\mathrm{A}, \mathrm{B}$ and $\mathrm{C}$, there was no change in color, odor and appearance up to the observation period of 30 days at $8^{\circ} \mathrm{C}$ and $40^{\circ} \mathrm{C}$ using different storage conditions, also the Formulations $\mathrm{A}, \mathrm{B}$ and $\mathrm{C}$ were stable [6].

\subsection{2. $\mathrm{pH}$ of the prepared formulations}

It was found to be in the range of 6.62 to 7.08 , kept at different storage conditions for 30 days. $\mathrm{pH}$ of the formulations and base kept at $8^{\circ} \mathrm{C}$ for one month did not show much change and data were significant over control (base) during one month $(\mathrm{p}<0.05)$. Interestingly at $40^{\circ} \mathrm{C}$, formulation A exhibited elevated change in $\mathrm{pH}$ (7.08), while the others remained slightly stable during one-month study. Data of formulations A, B and C at $40^{\circ} \mathrm{C}$ were found to be significant Table 2 .

\subsubsection{Viscosity test}

Viscosity and Rheological properties of the formulations were found to be $7869 \pm 3.54$ to $7968 \pm 3.92$. The data of viscosity in formulations A, B, C and Control at $8^{\circ} \mathrm{C}$ and at $40^{\circ} \mathrm{C}$ were significant as shown in Table 2 .

\subsubsection{Centrifugation}

Centrifugation test for base and formulation kept at different storage conditions were performed for 30 days. No phase separation after centrifugation was found in formulations $\mathrm{A}, \mathrm{B}, \mathrm{C}$ and base at 8 and $40^{\circ} \mathrm{C}$ during one-month study Table 1.

\subsubsection{Spreadability}

Spreadability of the base and formulations (A, B and C) were studied and found to in the range of $8.3 \pm 0.09$ to $10.0 \pm 0.01$. All the formulations and base were found to possess good spreadability.

\subsubsection{Washability}

Formulations were applied on the skin and then ease and extent of washing with water were checked manually. All the formulations exhibited good washability and left no traces over the skin on washing with water due to non-greasy properties.

\subsection{Acid value, peroxide value and total fatty matter determination}

Acid value, peroxide value and total fatty matter for the base and formulations kept at different storage conditions were observed for 30 days and the values for base and formulations $\mathrm{A}, \mathrm{B}, \mathrm{C}$ were found within the range Table 2. Acid value was found to be in the range of 2.30 to 2.91, peroxide value was found to be in the range of 1.64 to 1.88 and total fatty matters were found to be in the range of 15.01 to 15.5 for the formulations and base kept at different storage conditions for 30 days. Data of acid values of the formulations and base were found to be significant $(p<0.05)$ during one month of stability study. Peroxide value data in formulations A, 
$\mathrm{B}, \mathrm{C}$ and control at $8^{\circ} \mathrm{C}$ and $40^{\circ} \mathrm{C}$ were found to be significant $(p<0.05)$. Total fatty matter data were found to be significant in all except formulation A, B, C and control at 8 and $40^{\circ} \mathrm{C}$ Table 2 .

Table 1. Physical study of the prepared formulations during one month.

\begin{tabular}{|c|c|c|c|c|c|c|}
\hline \multirow{3}{*}{$\begin{array}{l}\text { Duration } \\
\text { Parameter }\end{array}$} & \multicolumn{6}{|c|}{ Storage Conditions } \\
\hline & \multicolumn{2}{|c|}{7 days } & \multicolumn{2}{|c|}{15 days } & \multicolumn{2}{|c|}{30 days } \\
\hline & $8^{\circ} \mathrm{C}$ & $40^{\circ} \mathrm{C}$ & $8^{\circ} \mathrm{C}$ & $40^{\circ} \mathrm{C}$ & $8^{\circ} \mathrm{C}$ & $40^{\circ} \mathrm{C}$ \\
\hline \multicolumn{7}{|l|}{ Appearance } \\
\hline Formulation A & Semisolid & Semisolid & Semisolid & Semisolid & Semisolid & Slightly Liquid \\
\hline Formulation B & Semisolid & Semisolid & Semisolid & Semisolid & Semisolid & Semisolid \\
\hline Formulation C & Semisolid & Semisolid & Semisolid & Semisolid & Semisolid & Slightly Liquid \\
\hline Control or Base & Semisolid & Semisolid & \multirow[t]{2}{*}{ Semisolid } & Semisolid & Semisolid & Semisolid \\
\hline Color & & & & & & \\
\hline Formulation A & Yellow & Yellow & Yellow & Yellow & Yellow & Dark Yellow \\
\hline Formulation B & Yellow & Yellow & Yellow & Yellow & Yellow & Yellow \\
\hline Formulation $\mathrm{C}$ & Yellow & Yellow & Yellow & Yellow & Yellow & Dark Yellow \\
\hline Control or Base & Colorless & Colorless & Colorless & Colorless & Colorless & Colorless \\
\hline Odour & & & & & & \\
\hline Formulation A & Characteristic & Characteristic & Characteristic & Characteristic & Characteristic & Bad Smell \\
\hline Formulation B & Characteristic & Characteristic & Characteristic & Characteristic & Characteristic & Characteristic \\
\hline Formulation C & Characteristic & Characteristic & Characteristic & Characteristi & Characteristic & Characteristic \\
\hline Control or Base & Characteristic & Characteristic & Characteristic & Characteristic & Characteristic & Characteristic \\
\hline Centrifugation te & & & & & & \\
\hline Formulation A & NSL & NSL & NSL & NSL & NSL & NSL \\
\hline Formulation B & NSL & NSL & NSL & NSL & NSL & NSL \\
\hline Formulation C & NSL & NSL & NSL & NSL & NSL & NSL \\
\hline Control or Base & NSL & NSL & NSL & NSL & NSL & NSL \\
\hline
\end{tabular}

\subsection{Patch test evaluation of volunteers}

Patch test was performed to check the safety of the formulation and base on human skin. The prepared formulations and base were applied on the forearms of volunteers for $48 \mathrm{~h}$ [6]. The values obtained are shown in Table 3. The data showed that the parameters namely; ease of application was observed to be in the range of $2.4 \pm 0.2341$ to $3.9 \pm 0.3214$. The spreadability result of formulations and base were observed to be in the range of $2.5 \pm 0.2537$ to $3.7 \pm 0.2321$. Sense just after application of the formulations and base were found to be in the range of $2.5 \pm 0.2642$ to $4.0 \pm 0.2775$. Irritation as well as sense of softness on application for formulations A, B and $C$ over forearms of volunteers, was recorded in the range of $2.56 \pm 0.2212$ to $4.4 \pm 0.3431$. All the results of the patch test were quite good as compared to the base. With paired sample $t$-test, it was evident that the effects of formulations and base were highly significant $(p<0.001)$ regarding all parameters of patch test. Volunteers reported that there was no irritation, redness after application of the prepared formulations A, B and C. Results of the patch test are shown in Figure 1.

\subsection{Stability of polyherbal gel}

Stability of the base and formulations (A, B and C) were studied at different storage conditions and assessed for their physical characteristics like color, appearance and odor (for 30 days) [6]. The results are shown in Table 1. Formulation A showed no significant changes in appearance, odor and color after 30 days.

\subsection{Antimicrobial activity}

It was determined by measuring the diameter of zone of inhibition. The results obtained in the evaluation of the antimicrobial activity of Formulation A, B, C and control(base) against the selected microorganisms are shown in Table 4 and Figure 2A, 2B, 2C and 2D. Base showed zone of inhibition in the range of $8.98 \pm 0.7943$ to $9.76 \pm 0.8798$ against $S$. aureus, E.coli B. subtilis and A. niger. Formulation $C$ showed better zone of inhibition in the range of $15.87 \pm 0.7804$ to $19.01 \pm 0.6542$ as compared to Formulation A, B and base. Thus, formulation $C$ exhibited maximum activity against selected strains due to high amount of herbal extracts in comparison to others. The results were found to be statistically significant $(p<0.05)$. 
Table 2. Chemical study of the prepared formulations during one month.

\begin{tabular}{|c|c|c|c|c|c|c|}
\hline \multirow{3}{*}{$\begin{array}{l}\text { Duration } \\
\text { Parameter }\end{array}$} & \multicolumn{2}{|l|}{7 days } & \multicolumn{2}{|l|}{15 days } & \multicolumn{2}{|l|}{30 days } \\
\hline & \multicolumn{6}{|c|}{ Storage Conditions } \\
\hline & $8^{\circ} \mathrm{C}$ & $40^{\circ} \mathrm{C}$ & $8^{\circ} \mathrm{C}$ & $40^{\circ} \mathrm{C}$ & $8^{\circ} \mathrm{C}$ & $40^{\circ} \mathrm{C}$ \\
\hline \multicolumn{7}{|l|}{$\mathrm{pH}$} \\
\hline Formulation A & $6.63 \pm 0.22$ & $6.91 \pm 0.17$ & $6.87 \pm 0.19$ & $6.93 \pm 0.23$ & $6.80 \pm 0.38$ & $7.08 \pm 0.14$ \\
\hline Formulation B & $6.90 \pm 0.17$ & $6.91 \pm 0.19$ & $6.80 \pm 0.35$ & $6.82 \pm 0.54$ & $6.91 \pm 0.42$ & $6.81 \pm 0.98$ \\
\hline Formulation C & $6.98 \pm 0.20$ & $6.95 \pm 0.25$ & $6.90 \pm 0.35$ & $7.01 \pm 0.44$ & $6.98 \pm 0.24$ & $6.71 \pm 0.88$ \\
\hline Control or Base & $6.71 \pm 0.25$ & $6.62 \pm 0.30$ & $6.78 \pm 0.19$ & $6.85 \pm 0.54$ & $6.80 \pm 0.25$ & $6.85 \pm 0.35$ \\
\hline \multicolumn{7}{|c|}{ Viscosity and Rheological studies (Cps) } \\
\hline Formulation A & $7968 \pm 3.92$ & $7962 \pm 2.33$ & $7958 \pm 3.50$ & $7952 \pm 4.01$ & $7945 \pm 2.90$ & $7939 \pm 3.09$ \\
\hline Formulation B & $7939 \pm 2.67$ & $7934 \pm 3.65$ & $7925 \pm 4.01$ & $7918 \pm 3.65$ & $7910 \pm 4.06$ & $7903 \pm 3.56$ \\
\hline Formulation C & $7918 \pm 2.65$ & $7910 \pm 3.90$ & $7895 \pm 2.65$ & $7894 \pm 4.11$ & $7885 \pm 4.03$ & $7865 \pm 3.96$ \\
\hline Control or Base & $7911 \pm 2.12$ & $7898 \pm 2.76$ & $7891 \pm 3.76$ & $7882 \pm 4.04$ & $7876 \pm 3.65$ & $7869 \pm 3.54$ \\
\hline \multicolumn{7}{|c|}{ Spreadability $\left(\mathrm{gm}-\mathrm{cm}^{2}\right)$} \\
\hline Formulation A & $8.4 \pm 0.01$ & $8.4 \pm 0.04$ & $8.3 \pm 0.09$ & $8.4 \pm 0.01$ & $8.3 \pm 0.06$ & $8.3 \pm 0.10$ \\
\hline Formulation B & $9.8 \pm 0.02$ & $9.8 \pm 0.03$ & $9.8 \pm 0.08$ & $9.7 \pm 0.04$ & $9.6 \pm 0.08$ & $9.7 \pm 0.09$ \\
\hline Formulation C & $9.9 \pm 0.03$ & $9.9 \pm 0.02$ & $9.9 \pm 0.06$ & $9.8 \pm 0.06$ & $9.8 \pm 0.07$ & $9.7 \pm 0.09$ \\
\hline Control or Base & $10.0 \pm 0.01$ & $10.0 \pm 0.03$ & $10.0 \pm 0.04$ & $10.0 \pm 0.05$ & $9.5 \pm 0.10$ & $9.5 \pm 0.07$ \\
\hline \multicolumn{7}{|l|}{ Acid Value } \\
\hline Formulation A & $2.65 \pm 0.12$ & $2.59 \pm 0.20$ & $2.63 \pm 0.22$ & $2.74 \pm 0.16$ & $2.85 \pm 0.23$ & $2.91 \pm 0.23$ \\
\hline Formulation B & $2.55 \pm 0.15$ & $2.57 \pm 0.19$ & $2.57 \pm 0.21$ & $2.75 \pm 0.21$ & $2.66 \pm 0.23$ & $2.79 \pm 0.15$ \\
\hline Formulation C & $2.56 \pm 0.10$ & $2.76 \pm 0.16$ & $2.54 \pm 0.12$ & $2.76 \pm 0.21$ & $2.45 \pm 0.16$ & $2.76 \pm 0.17$ \\
\hline Control or Base & $2.30 \pm 0.06$ & $2.37 \pm 0.09$ & $2.45 \pm 0.11$ & $2.43 \pm 0.05$ & $2.46 \pm 0.15$ & $2.50 \pm 0.17$ \\
\hline \multicolumn{7}{|l|}{ Peroxide Value } \\
\hline Formulation A & $1.49 \pm 0.23$ & $1.53 \pm 0.25$ & $1.55 \pm 0.30$ & $1.62 \pm 0.25$ & $1.64 \pm 0.28$ & $1.67 \pm 0.30$ \\
\hline Formulation B & $1.61 \pm 0.11$ & $1.64 \pm 0.09$ & $1.70 \pm 0.15$ & $1.76 \pm 0.22$ & $1.78 \pm 0.25$ & $1.85 \pm 0.32$ \\
\hline Formulation C & $1.65 \pm 0.10$ & $1.70 \pm 0.07$ & $1.72 \pm 0.09$ & $1.79 \pm 0.20$ & $1.80 \pm 0.21$ & $1.88 \pm 0.33$ \\
\hline Control or Base & $1.64 \pm 0.09$ & $1.67 \pm 0.12$ & $1.70 \pm 0.16$ & $1.73 \pm 0.12$ & $1.74 \pm 0.15$ & $1.79 \pm 0.21$ \\
\hline \multicolumn{7}{|l|}{ Total fatty matters } \\
\hline Formulation A & $15.55 \pm 0.23$ & $15.42 \pm 0.32$ & $15.34 \pm 0.26$ & $15.30 \pm 0.15$ & $15.24 \pm 0.32$ & $15.18 \pm 0.35$ \\
\hline Formulation B & $15.40 \pm 0.12$ & $15.32 \pm 0.15$ & $15.25 \pm 0.21$ & $15.28 \pm 0.18$ & $15.20 \pm 0.23$ & $15.10 \pm 0.30$ \\
\hline Formulation C & $15.33 \pm 0.19$ & $15.32 \pm 0.30$ & $15.20 \pm 0.23$ & $15.13 \pm 0.28$ & $15.07 \pm 0.29$ & $15.00 \pm 0.32$ \\
\hline Control or Base & $15.35 \pm 0.10$ & $15.49 \pm 0.11$ & $15.31 \pm 0.23$ & $15.25 \pm 0.21$ & $15.20 \pm 0.26$ & $15.01 \pm 0.24$ \\
\hline
\end{tabular}


Table 3. Evaluation of prepared formulations on skin (Patch test) in human volunteers

\begin{tabular}{lllll}
\hline Variable & $\begin{array}{l}\text { Average point } \\
\text { for Control } \pm \\
\text { SEM }\end{array}$ & $\begin{array}{l}\text { Average points for } \\
\text { Formulation A } \pm \\
\text { SEM }\end{array}$ & $\begin{array}{l}\text { Average points for } \\
\text { Formulation B } \pm \\
\text { SEM }\end{array}$ & $\begin{array}{l}\text { Average points for } \\
\text { Formulation C } \pm \\
\text { SEM }\end{array}$ \\
\hline Ease of application & $2.4 \pm 0.2341$ & $3.9 \pm 0.3214$ & $3.8 \pm 0.1765$ & $3.8 \pm 0.2343$ \\
Spread ability & $2.5 \pm 0.2537$ & $3.4 \pm 0.2142$ & $3.6 \pm 0.2621$ & $3.7 \pm 0.2321$ \\
Sense just after application & $2.5 \pm 0.2642$ & $4.0 \pm 0.2775$ & $3.5 \pm 0.2227$ & $3.8 \pm 0.1243$ \\
Sense on Long term & $2.4 \pm 0.2361$ & $3.8 \pm 0.2794$ & $3.7 \pm 0.2632$ & $3.9 \pm 0.1986$ \\
Irritation & $3.7 \pm 0.2735$ & $4.4 \pm 0.3431$ & $4.0 \pm 0.2741$ & $4.2 \pm 0.2012$ \\
Sense of softness & $2.56 \pm 0.2212$ & $3.7 \pm 0.2341$ & $3.8 \pm 0.2161$ & $3.9 \pm 0.2103$ \\
\hline
\end{tabular}

Table 4. Antimicrobial sensitivity result of the prepared formulations A, B, C and Control.

\begin{tabular}{lllll}
\hline \multirow{2}{*}{ Test organism } & \multicolumn{4}{c}{ Zone of inhibition $\mathbf{( m m )}$} \\
\cline { 2 - 5 } & Control & Formulation A & Formulation B & Formulation C \\
\hline S. aureus & $9.76 \pm 0.8798$ & $15.56 \pm 0.6012$ & $17.70 \pm 0.6609$ & $19.01 \pm 0.6542$ \\
E.coli & $9.65 \pm 0.7809$ & $11.45 \pm 0.8648$ & $13.76 \pm 0.6098$ & $15.87 \pm 0.7804$ \\
B. subtilis & $8.98 \pm 1.020$ & $13.33 \pm 0.6523$ & $15.65 \pm 1.0090$ & $17.68 \pm 1.0245$ \\
A. niger & $8.98 \pm 0.7943$ & $15.64 \pm 0.8090$ & $17.79 \pm 1.1565$ & $19.22 \pm 0.9807$ \\
\hline
\end{tabular}

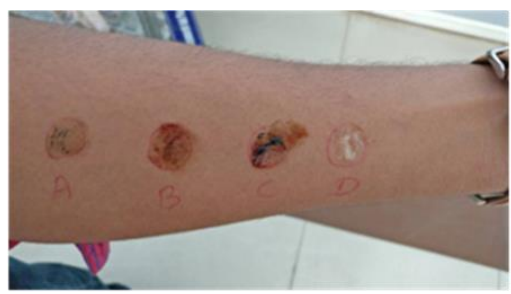

(i)

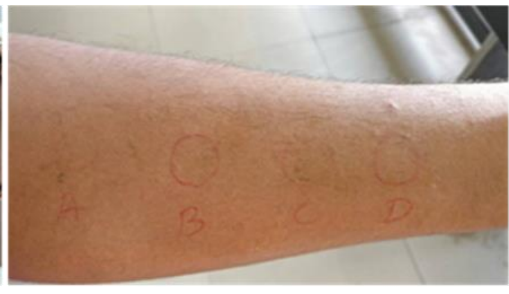

(ii)

Figure 1. A: Formulation A; B: Formulation B; C: Formulation C and D: Control (Base) (i) Formulation and control (base) application at time $=0 \mathrm{hr}$ (ii) Effect of all formulation and control at time $=48 \mathrm{hr}$ after application on forearms of volunteers.
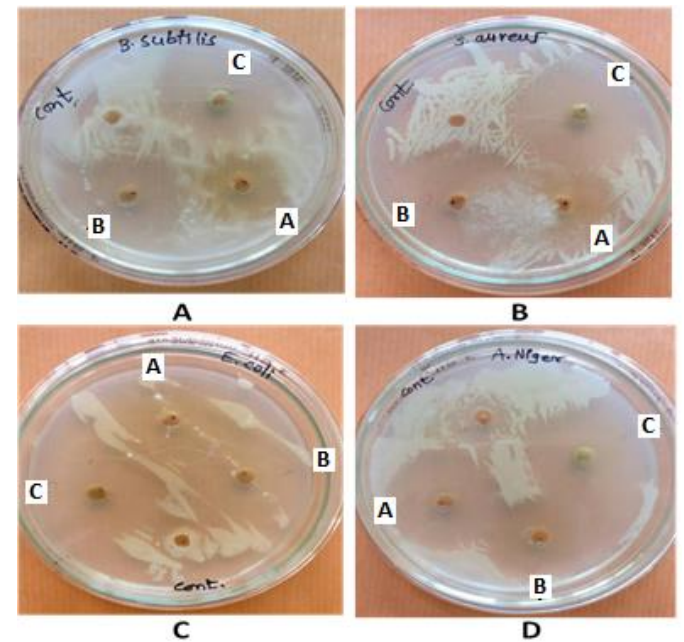

Figure 2. (A) Zone of inhibition of control and herbal formulations A, B, C and control against B. subtilis (B) of inhibition of control and herbal formulations v against $S$. aureus (C) Zone of inhibition of control and herbal formulations $\mathrm{C}$ and control against $E$. Coli (D) Zone of inhibition of control and herbal formulations $\mathrm{C}$ and control against $A$. niger. 


\section{DISCUSSION}

Plants are considered to be a vital source of potentially useful constituents for the development of new therapeutic agents, as most of them are safe with less or no side effect(s). Topical application of gels at pathological sites offer great advantages in a faster release of a drug directly to site of action as compared to cream and ointment $[7,8]$. Nowadays, gels have been widely used as a vehicle for topical delivery of drugs. Extracts of plants and herbs with specific medicinal properties can be incorporated in this dosage form as active ingredients in order to additional benefits [6, 37] S. aureus [48], E. coli, B. subtilis [49] and A. niger [50] are amongst the commonest pathogens that can cause skin infections. The antimicrobial properties of Azadirachta indica [9, 10, 14, 17, 50], Ocimum sanctum [25], Adhatoda vasica [28, 29], Piper betle [30-32] and Pongamia pinnata [35-36] plants have been previously investigated on some plant and human pathogens. However, their application and use in the raw form on to the skin surface is difficult therefore the extracts of these plants were developed in the form of gel formulation.

Cosmetically, the chemical constituents of Azadirachta indica, Adhatoda vasica, Piper betle, Ocimum tenuiflorum and Pongamia pinnata are considered to be antiseptic and natural preservatives.

Herbal cosmetic products are assumed to be safe for longer periods of time. However, quality control for efficacy and safety of herbal cosmetic products is of paramount importance; and quality control tests must therefore be carried out for these preparations. Stability studies and patch test are well known methods which will prove its efficacy and efficiency of the cosmetic herbal formulations $[6,37]$ Short term stability studies as per ICH guidelines, revealed that the $\mathrm{pH}$ of all the formulations and base indicated variability at different storage conditions. Viscosity, Rheological studies, Spreadability, Acid Value, Peroxide Value and Total fatty matters showed minimal variations in the results which proved that all the prepared formulations are stable for 8 and $40^{\circ} \mathrm{C}$. Applicability of the herbal formulation was proved to be satisfactory from the results of viscosity and spreadability. In our studies it was observed that the prepared formulations readily spread on application to the skin or affected part and homogeneity confirmed no lumps, respectively. Also, the physicochemical parameters applied in the testing of stability of cosmetics formulations made apparent consequences that formulations $\mathrm{C}$ is much better than formulations $\mathrm{A}, \mathrm{B}$ and base due to its relatively higher concentration of active constituents.

Literature surveys revealed that individually all extracts has potentially been known for their antimicrobial activity. However, no literature is available related to the formulation of a polyherbal formulation containing the extracts of Azadirachta indica, Adhatoda vasica, Piper betle, Ocimum tenuiflorum and Pongamia pinnata.

Figure 1 depicts the results of the patch test, which exhibited no irritation, redness on underarm after application of formulation A, B and C as reported by volunteers. Also, the results of washability test proved non-greasy properties of all prepared formulations.

This study clearly indicated that formulation A, B and C which possessed plant extracts were more potent than the base. The possible explanation for this is the presence of active constituents of plants which exhibit antimicrobial activity. But as compared with other formulations the potency of Formulation C was found to be greater.

\section{CONCLUSION}

Results of the studies revealed that the prepared polyherbal formulations A, B and C which comprised of ethanolic extract of Azadirachta indica, Adhatoda vasica, Piper betle, Ocimum tenuiflorum and Pongamia pinnata in a concentration of $0.1,0.3$ and $0.5 \%$, respectively produced no skin irritation after performing patch test on the underarm of human volunteers for 24 hours. Also the physical analysis and stability studies of the prepared polyherbal gel proved potency and efficacy. Thus, these formulations can be used safely on human skin. The effective activity exhibited by the polyherbal formulations may be attributed to the synergistic action of the plants constituents present in the formulation. The high amount of plant extracts $(0.5 \%)$ increased the antimicrobial activity of the formulation.

\section{MATERIALS AND METHODS}

\subsection{Chemicals}

Analytical grade chemicals were used for the study. The solid media and broth used for microbial culture were procured from Hi-Media Pvt. Limited, Bombay, India. Carbopol 940 (Merck Ltd), propylene 
glycol-400 (SD Fine Chemical Ltd), Ethanol (Merck Ltd), methyl paraben (Supreme Chemicals), propyl paraben (Supreme Chemicals), Triethanolamine (SD Fine Chemical Ltd), EDTA (S.D Fine lab India).

\subsection{Collection and extraction of plants parts}

Fresh leaves of Azadirachta indica, Ocimum tenuiflorum, Adhatoda vasica and seeds of Pongamia pinnata and Piper betle were collected from the Western Ghat regions of Maharashtra. The taxonomical identification of the collected plant species was done at Department of Botany, YC College of Science, Karad, Maharashtra, India. The plant material was dried in a hot air oven at $40^{\circ} \mathrm{C}$. The plant materials were coarsely powdered separately by using a grinding mill. About $30 \mathrm{~g}$ of each powder specimen were defatted with petroleum ether $\left(60-80^{\circ} \mathrm{C}\right)$ in a Soxhlet apparatus followed by its extraction with ethanol. The obtained extracts were further concentrated on a rotary evaporator and were kept in a vacuum dryer till further use.

\subsection{Preparation of polyherbal gel}

Formulation A, B and C were prepared which comprised of ethanolic extract of Azadirachta indica, Adhatoda vasica, Piper betle, Ocimum tenuiflorum and Pongamia pinnata in a concentration of $0.1,0.3$ and $0.5 \%$, respectively as shown in Table 5. Carbapol- 940, propylene glycol 400, ethanol, methyl paraben, propyl paraben, EDTA and tri-ethanolamine were used to prepare $100 \mathrm{gm}$ of gel by adding sufficient quantity of distilled water. Water required for these formulations was divided into two parts. In one part the exact amount of extract was dissolved and to this calculated quantity of propylene glycol 400 and ethanol was added and in other part, Carbapol-940 was dissolved and to this solution methyl paraben, propyl paraben and EDTA was added. Both of the solutions were mixed in a beaker and tri-ethanolamine was added to the mixture drop wise to obtain the gel consistency. It was stirred by using propeller for 2 hours at $500 \mathrm{rpm}$ to obtain a homogenous gel, devoid of any entrapped air bubbles. Various formulation batches were prepared according to the Table 5. Plant extracts were excluded to make the Gel base. The prepared gel formulations and base were kept at room temperature for 24 hours.

Table 5. Formulation table of Gel base and Polyherbal gels.

\begin{tabular}{|c|c|c|c|c|c|}
\hline Ingredients & $\begin{array}{c}\text { Quantity } \\
\text { taken in (\%) } \\
\text { for Gel base }\end{array}$ & $\begin{array}{c}\text { Quantity taken } \\
\text { in (\%) for } \\
\text { Formulation A }\end{array}$ & $\begin{array}{c}\text { Quantity taken } \\
\text { in (\%) for } \\
\text { Formulation B }\end{array}$ & $\begin{array}{c}\text { Quantity taken } \\
\text { in }(\%) \text { for } \\
\text { Formulation C }\end{array}$ & Role \\
\hline Carbopol 940 & 1.0 & 1.0 & 1.0 & 1.0 & Gelling agent \\
\hline Extract of each drug & ----- & 0.1 & 0.3 & 0.5 & $\begin{array}{l}\text { Antibacterial } \\
\text { activity }\end{array}$ \\
\hline Propylene glycol 400 & 4.0 & 4.0 & 4.0 & 4.0 & Base \\
\hline Ethanol & 3.0 & 3.0 & 3.0 & 3.0 & Solvent \\
\hline Methyl paraben & 0.2 & 0.2 & 0.2 & 0.2 & Preservative \\
\hline Propyl paraben & 0.02 & 0.02 & 0.02 & 0.02 & Preservative \\
\hline EDTA & 0.03 & 0.03 & 0.03 & 0.03 & Chelating agent \\
\hline Triethanolamine & 1.2 & 1.2 & 1.2 & 1.2 & pH adjustment \\
\hline Water & Q.S. 100 & Q.S 100 & Q.S 100 & Q.S 100 & Aqueous base \\
\hline
\end{tabular}

\subsection{Evaluation tests for Polyherbal gel}

\subsubsection{Appearance and homogeneity}

The prepared gels and control (base) were tested for physical appearance and homogeneity by visual observation [6].

\subsection{2. $p H$}

Digital $\mathrm{pH}$ meter (Systronics digital-DI-707) was used to determine $\mathrm{pH}$ of the prepared formulations and control (base) [6]. 3 gm of gel was accurately weighed and dispersed in $30 \mathrm{~mL}$ of distilled water and stored for two hours, then $\mathrm{pH}$ was measured separately $[6,37]$. The measurement of $\mathrm{pH}$ of each formulation was done in triplicate and the average values have been represented in Table 2. 


\subsubsection{Viscosity and rheological studies}

Brookfield viscometer (DV-III programmable Rheometer) instrument was used to determine the rheological characteristics of control (base) and Formulations at $25^{\circ} \mathrm{C}$ [6]. The measurement was made over the whole range of speed settings from $10 \mathrm{rpm}$ to $100 \mathrm{rpm}$ with 30 seconds between two successive speeds and then in a descending order $[6,37]$.

\subsubsection{Spreadability}

A special apparatus as suggested by Mutimer et al., 1956; was designed for determining spreadability of the prepared gel formulations $[6,38]$. An excess of gel sample was placed between the two glass slides and a $1000 \mathrm{~g}$ weight was placed in slides for 5 minutes to compress a sample to uniform thickness [6,37]. Weight (50 gm) was added to the pan. The time required to separate the two slides was taken as a measure of spreadability [6]. Lesser the time taken for separation of two slides, better the spreadability. It was calculated by using the formula:

$$
\mathrm{S}=\mathrm{M} \cdot \mathrm{L} / \mathrm{t}
$$

Where $\mathrm{M}$ is the weight $(\mathrm{g})$ tied to the upper glass slide; $\mathrm{L}$ is the length $(\mathrm{cm})$ moved on the glass slide and $t$ is time to separate the slide (sec).

\subsubsection{Washability}

Formulations were applied on the skin and then ease and extent of washing with water were determined manually [6].

\subsection{Chemical tests}

\subsubsection{Acid value}

$0.5 \mathrm{gm}$ of gel was taken and dissolved in 10 times of absolute alcohol. It was heated on a hot plate for 5 min and 2 to 3 drops of phenolphthalein indicator was added to it and titrated with $0.1 \mathrm{~N} \mathrm{KOH}$ until faint pink color appeared [39].

Acid Value $=56.1 \times$ Titre value $\times \mathrm{N}$ of $\mathrm{KOH} /$ Weight of sample.

\subsubsection{Peroxide value}

In a separate $200 \mathrm{~mL}$ flask, 5 gm of gel sample of control (base) and formulations, $30 \mathrm{~mL}$ of acetic acid and chloroform solution were added and swirled gently [6]. Then $0.5 \mathrm{~mL}$ of potassium iodide solution was added with continuous shaking and $30 \mathrm{~mL}$ of water was added thereafter. Finally the solution was then titrated with $0.1 \mathrm{M}$ sodium thiosulfate solution with vigorous shaking. End point of titration was noted when yellow color almost disappears. Then $0.5 \mathrm{~mL}$ of $1 \%$ starch was added and titration was continued with vigorous shaking to release all iodine from chloroform layer, until blue color disappeared [6, 40].

Peroxide value $=\mathrm{S} \times \mathrm{M} \times 1000 / \mathrm{gm}$ sample

Where $\mathrm{S}=\mathrm{mL}$ of sodium thiosulfate and $\mathrm{M}=$ Molarity of sodium thiosulfate solution.

\subsubsection{Total fatty matter determination}

2 gm of gel sample and 20-25 mL of 1:1 dilute $\mathrm{HCl}$ was taken into the $200 \mathrm{~mL}$ flask, then the solution was heated on a water bath till the solution becomes clear [6]. The sample (aqueous phase) was drawn in a 250 $\mathrm{mL}$ separating funnel and then allowed to cool at room temperature. $50 \mathrm{~mL}$ of petroleum ether (organic phase) was then added in the funnel and shaked and left for separation to occur [6]. The organic phase was collected. The above aqueous layer partitioned twice with same quantity of petroleum ether. The organic layers were collectively evaporated to obtain residue which was consequently washed with water. The residue was filtered and sodium sulfate was added to it. The mixture was again filtered, the extract was dried and the content was determined $[6,41]$.

Total fatty matter $(\%)$ by mass $=100 \times \mathrm{M}_{1} / \mathrm{M}_{2}$;

$$
\mathrm{M}_{1}=\text { mass of residue; } \mathrm{M}_{2}=\text { mass of sample in gram } \text {. }
$$




\subsection{Product evaluation on skin (Patch test)}

Twenty healthy human volunteers were selected whose ages were in between (20-35) years. Consent form was filled by each human volunteer prior starting the study [6]. Volunteers having serious skin diseases, asthma were excluded from the study. Patch test was performed on the forearms of each volunteer to determine any possible reaction(s) to the formulation [6, 42]. The prepared formulations A, B and Calong with control (base) were applied on the forearms of the volunteers separately. Adhesive tape was used to fix them in place and the test sites were marked. The patches were left in place for $48 \mathrm{~h}$, during which care was taken not to wash the applied area [6]. The patches were removed and observation (redness, itching, or blemishes) with their reading was taken one hour later. These visible signs along with any itchy or irritable sensations indicated that there is something wrong to the product. Clear skin devoid of aforesaid visible signs indicated that the product is safe to use $[6,40,43]$.

\subsection{Stability of polyherbal gel}

Short term stability (for 30 days) of control (base) and formulations (A, B and C) were verified at $8 \pm 0.1$ and $40 \pm 0.1{ }^{\circ} \mathrm{C}$ storage conditions (in incubator) with $75 \%$ relative humidity $(\mathrm{RH})$ as mentioned by Pandey et al. by checking for their physical characteristics like color, appearance, odor and centrifugation test [6].

\subsection{Antibacterial activity of polyherbal gel}

The prepared formulations and control (base) were screened for their antibacterial activity by Disc plate method [6, 44-47]. It was tested on nutrient medium against S. aureus, B. subtilis, A. niger and E. coli which are representative types of Gram positive and Gram negative organisms. The activity was determined by measuring the diameter of zone of inhibition recorded [6]. The test strains of S. aureus, B. subtilis, A. niger and E. coli were collected from Department of Microbiology, YC College, Karad (415124), Maharashtra, India. The plates were inoculated with test cultures and were incubated at $37 \pm 1^{\circ} \mathrm{C}$ for $24 \mathrm{~h}$. The next day, the wells $(6 \mathrm{~mm}$ diameter) were made with help of $6 \mathrm{~mm}$ diameter cork borer and the wells were loaded with prepared formulations namely A, B and C along with base as a control. After $24 \mathrm{~h}$ of incubation, the test determined the efficacy of the product in terms of zone of inhibition of the organism.

\subsection{Statistical analysis}

The measured values obtained for different parameters were analyzed using SPSS 20 software and results were further tested by paired sample $t$ test.

Acknowledgements: Authors are thankful to Dr. C. S. Magdum, Principal, Rajarambapu College of Pharmacy, Kasegaon for providing necessary facilities to carry out the research work.

Author contributions: Concept - S.D.B., M.A.B., D.S.R., G.H.W.; Design - S.D.B., M.A.B., D.S.R., G.H.W., P.D.K., S.S.K.; Supervision - S.D.B., M.A.B., D.S.R., S.Y.K.; Resource - S.D.B., M.A.B., D.S.R., G.H.W., P.D.K.; Materials - S.D.B., G.H.W., P.D.K., S.S.K., S.Y.K.; Data Collection \&/or Processing - S.D.B., M.A.B., S.S.K., S.Y.K.; Analysis \&/or Interpretation - S.D.B., D.S.R., G.H.W., P.D.K.; Literature Search - S.D.B., D.S.R., G.H.W.; Writing - S.D.B., M.A.B., D.S.R., G.H.W.; Critical Reviews - S.D.B., M.A.B., D.S.R., G.H.W., S.Y.K., P.D.K., S.S.K.

Conflict of interest statement: We wish to confirm that there are no known conflicts of interest associated with this publication and there has been no significant financial support for this work that could have influenced its outcome.

\section{REFERENCES}

[1] Babu M, Gnanamani A, Radhakrishan N, Priya K. Healing potential of Datura alba on burn wounds in albino rats. J Ethnopharmacol. 2002; 83(3): 193-199.

[2] Rajesh T, Roy AK, Erumalla VNR, Goli D, Basha SJ. Development and evaluation of antimicrobial ointment formulation containing extracts of Ocimum sanctum, Anthocephalus cadamba, Allium sativum and Origanum vulgare. World J Pharm Res. 2014; 3(5): 398-402.

[3] Shaikh AM, Shrivastava B, Apte KG, Navale SD. Medicinal plants as potential source of anticancer agents: A review. J Pharmacogn Phytochem. 2016; 5 (2): 291-295.

[4] Aburjai T, Natsheh FM. Plants used in cosmetics. Phytother Res. 2003; 17(9): 987-990. 
[5] Ali A, Akhtar N, Mumtaz AM, Khan MS, Iqbal FM, Zaidi SS. In vivo skin irritation potential of a cream containing Moringa oleifera leaf extract. Afr J Pharm Pharmacol. 2013; 7(6): 289-293.

[6] Pandey S, Seth A, Tiwari R, Singh S, Behl HM, Singh S. Development and evaluation of antimicrobial herbal cosmetic preparation. Afr J Pharm Pharmacol. 2014; 8(20): 514-518.

[7] Avinash S, Gowda DV, Suresh J, Aravind RAS, Srivastava A, Osmani RAM. Formulation and evaluation of topical gel using Eupatorium glandulosum michx. for wound healing activity. Pharm Lett. 2016; 8(9): 255-266.

[8] Patel H, Panchal MS, Shah S, Vadalia KR. formulation and evaluation of transdermal gel of sildenafil citrate. Int J Pharm Res Allied Sci. 2012; 1(3): 103-118.

[9] Apisariyakul A, Vanittanakom N, Buddhasukh D. Antifungal activity of turmeric oil extracted from Curcuma longa (Zingiberaceae). J Ethnopharmacol. 1995; 49(3): 163-169.

[10] Susmitha S, Vidyamol KK, Ranganayaki P, Vijayaragavan R. Phytochemical extraction and antimicrobial properties of Azadirachta indica (Neem). Glob J Pharmacol. 2013; 7(3): 316-320.

[11] Bishnu J, Govind PS, Buddha BB, Megh RB, Dinita S, Krishna S, Pandey J, Malla R. Phytochemical extraction and antimicrobial properties of different medicinal plants: Ocimum sanctum (Tulsi), Eugenia caryophyllata (Clove), Achyranthes bidentata (Datiwan) and Azadirachta indica (Neem). J Microbiol Antimicrob. 2011; 3(1): 1-7.

[12] Mahajan N, Rawal S, Verma M, Poddar M, Alok S. A phytopharmacological overview on Ocimum species with special emphasis on Ocimum sanctum. Biomed Prev Nutr. 2013; 3: 185-192.

[13] Hogade MG, Jalalpure SS, Bhinge SD. In vitro Anthelmintic Activity of bark of Azadirachta indica against Ascardi galli and Eudrilus eugeniae. J Nat Remedies. 2013; 14(01): 48-51.

[14] Alves PD, Brandão MGL, Nunan EA, Cristina D. Chromatographic evaluation and antimicrobial activity of Neem (Azadirachta indica A. Juss., Meliaceae) leaves hydroalcoholic extracts. Braz J Pharmacogn. 2009; 19(2): 510-515.

[15] Okpanyi SN, Ezeukwk GC. Anti-inflammatory and antipyretic activities of Azadirachta indica. Planta Med. 1981; 41(1): 34-39.

[16] Pillai NR, Santhakumari G. Toxicity studies on nimbidin. A potential antiulcer drug. Planta Med. 1984; b.50: $146-48$.

[17] Rao DVK, Singh K, Chopra P, Chabra PC, Ramanujalu G. In vitro antibactericidal activity of Neem oil. Indian J Med Res. 1986; 84: 314-316.

[18] Shukla R, Singh S, Bhandari CR. Preliminary clinical trial on antidiabetic actions of Azadirachta indica. Med Surg. 1973; 13: 11-22.

[19] Singh PP, Junnarkar AY, Reddi GS, Singh KV. Azadirachta indica neuro-psychopharmacological and antimicrobial studies. Fitoterapia. 1987; 58(4): 233-48.

[20] Tella A. The effects of Azadirachta indica in acute Plasmodium berghei malaria. Nig Med J. 1977; 7(3): 258-263.

[21] Bhargava KP, Sing N. Anti-stress activity of Ocimum sanctum. Indian J Med Res. 1981; 73: 443-451.

[22] Karthikeyan K. Chemo preventive effect of Ocimum sanctum on DMBA - induced hamster buccal pouch carncinogenesis. Oral Oncol. 1999; 35(1): 112-119.

[23] Maulik SK. Evaluation of antioxidant effectiveness of a few herbal plants. Free Radic Res. 1997; 27(2): $221-228$.

[24] Rai V, Iyer U, Mani UV. Effects of Tulsi (Ocimum sanctum) leaf powder supplementation on blood sugar levels, serum lipids, tissue lipids in diabetic rats. Plant Foods Hum Nutr. 1997; 50(1): 9-16.

[25] Mediratta PK, Sharma KK. Effect of essential oil of the leaves and fixed oil of the seeds of Ocimum sanctum on immune responses. J Med Arom Plant Sci. 2000; 22: 694-700.

[26] Singh S, Majumda DK. Evaluation of the gastric antiulcer activity of fixed oil of Ocimum sanctum. J Ethnopharmacol. 1999; 65(1): 13-19.

[27] Bhinge SD, Desai P, Magdum CS. In vitro anthelmintic activity of leaves extract of Adhatoda vasica nees. (Acanthaceae) against Eudrilus eugeniae. Dhaka Univ J Pharm Sci. 2015; 14(02): 17-18.

[28] Yadhav AK, Tangpu V. Anticestodal activity of Adhatoda vasica extract against Hymenolepis diminuta infections in rats. J Ethnopharmacol. 2008; 119(2): 322-24.

[29] Shrivastava N, Srivastava A, Banerjee A, Nivsarkar M. Antiulcer activity of Adhatoda vasica Nees. J Herb Pharmacother. 2000; 6(2): 43-49. 
[30] Shitut S, Pandit V, Mehta BK. The antimicrobial efficiency of Piper betle Linn leaf (stalk) against human pathogenic bacteria and phytopathogenic fungi. Cent Eur J Public Health. 1999; 7(3): 137-139.

[31] Pandita N, Varghese A, Mantri M, Kachwala Y. Anti-plaque activity of Piper betle leaf extracts. Planta Med. 2010; 76(12): 1296-1307.

[32] Hoque MM, Rattila S, Shishir MA, Bari ML, Inatsu Y, Kawamoto S. Antibacterial activity of ethanol extract of betel leaf (piper betle 1.) against some food borne pathogens. Bangladesh J Microbiol. 2011; 28(2): 58-63.

[33] Sajid ZI, Anwar F, Shabir G, Rasul G, Alkharfy KM, Gilani AH. Antioxidant, antimicrobial properties and phenolics of different solvent extracts from bark, leaves and seeds of Pongamia pinnata (L.) Pierre. Molecules. 2012; 17(4): 39173922. doi:10.3390/molecules17043917.

[34] Chakraborty D, Shah B. Antimicrobial, antioxidative andantihaemolytic activity of Piper betel L. leaf extracts. Int J Pharmacy Pharm Sci. 2011; 3(3): 192-198.

[35] Badole SL, Zanwar AA, Khopade AN, Bodhankar SL. In vitro antioxidant and antimicrobial activity cycloart-23-ene33,-25-diol (B2) isolated from Pongamia pinnata (L. Pierre). Asian Pac J Trop Med. 2011; 4(11): 910-916.

[36] Dayanand CD, Rani MS, Shetty J, Vegi PK, Kutty AVM. Evaluation of antibacterial activity of Pongamia pinnata Linn on pathogens of clinical isolates. Am J Phytomed Clin Therapeut. 2013; 1(8): 645-651.

[37] Bhinge SD, Bhutkar MA, Randive DS, Wadkar GH, Todkar SS, Kakade PM, Kadam PM. Development and evaluation of antimicrobial polyherbal gel. Ann Pharm Fr. 2017; 75(5): 349-358.

[38] Mutimer MN, Riffikin C, Hill JA, Marry E, Glickman CNG. Synthesis of methylsilyl derivates of procaine and their diffusion. J Am Pharm Assoc Sci. 1956; 45: 212-218.

[39] IFRA Analytical Method. Determination of the peroxide value. Indian Standard: Guideline hygienic manufacture of cosmetics "Specification for Skin Cream" IS No. 6608 2011; 978.

[40] Aswal A, Kalra M. A Rout. Preparation and evaluation of polyherbal cosmetic cream. Pharm Lett. 2013; 5(1): 83-88.

[41] Ergene U, Akcali Z, Ozbalci D, Nese N, Senol S. Desseminated Aspergillosis due to Aspergillus niger in immunocompetent patient: A case report. Case Rep Infect Dis. 2013: 1-3.

[42] Akhtar N, Khan BA, Khan MS, Mahmood T, Khan HMS, Iqbal M, Bashir S. Formulation development and moisturizing effects of a topical cream of Aloe vera extract. Int J Pharmacol Pharm Sci. 2011; 5(3): 128-136.

[43] Barbaud A, Gonçalo M, Bruynzeel D, Bircher A. Guidelines for performing skin tests with drugs in the investigation of cutaneous adverse drug reactions. Contact Derm. 2001; 45(6): 321-328.

[44] Bhinge SD, Hogade MG, Savali AS, Hariprassana RC, Magdum CS. Antibacterial activity of bark extract of Ficus glomerata roxb against some Gram positive and Gram negative bacteria. Indian Drugs. 2013; 50(5): 44-47.

[45] Chavan CB, Shinde UV, Hogade M, Bhinge S. Screening of in-vitro antibacterial assay of barleria prionitis L. J Herb Med Toxicol. 2010; 4: 193-196.

[46] Mathapati PS, Durgad SA, Bhinge SD. Synthesis and antimicrobial activity of benzimidazole derivative. Indian Drugs. 2012; 49(2): 17-25.

[47] Bhinge SD, Bhalke S, Savali AS, Hogade MG. Antimicrobial activity of ethanolic and aqueous fruit extract of Aegle marmelos. Deccan J Pharmacol. 2010; 1(4): 10-11.

[48] Martin M. Skin diseases induced by Staphylococcus aureus. CME Dermatol. 2008; 3: 20-30.

[49] Kumar CP, Chandra DS, Kumar DS. Antimicrobial activity of Ficus racemosa L. and Cissampelos pareira L. var. Hirsuta (DC) froman, against E. coli, P. aeruginosa, S. aureus and B. subtilis. Int Res J Pharm. 2012; 3(12): 151-153.

[50] Nayak A, Nayak RN, Soumya GB, Kishore B, Mithun K. Evaluation of antibacterial and antimicrobial efficacy of aqueous and alcoholic extracts of neem (Azadiractha indica) an in vitro study. IJARP. 2011; 2(1): 230-235. 